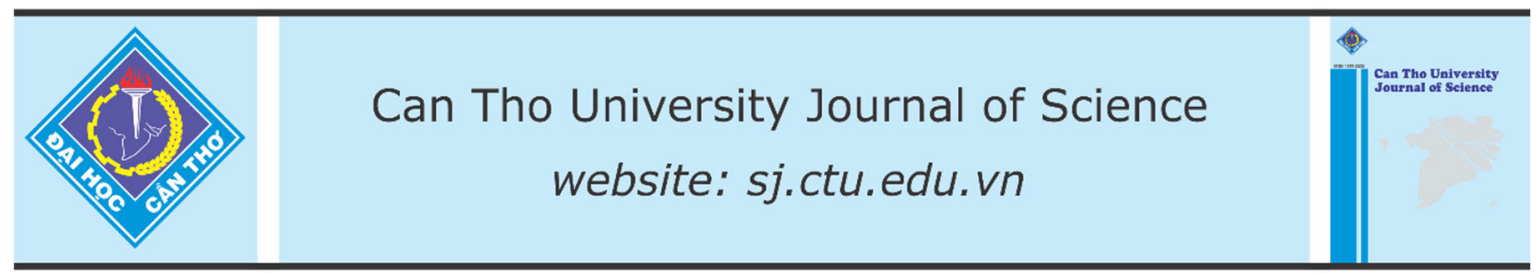

DOI: $10.22144 / c t u . j e n .2019 .015$

\title{
An evaluation female human resource in public administration with study case in the Mekong Delta
}

Nguyen Khanh Linh

School of Political Science, Can Tho University, Vietnam

Correspondence: Nguyen Khanh Linh (email:nklinh@ctu.edu.vn)

\section{Article info.}

Received 22 Mar 2018

Revised 24 Aug 2018

Accepted 29 Mar 2019

\section{Keywords}

Mekong Delta, leadership, public administration, women

\begin{abstract}
Mekong Delta is one of Vietnam's extensive areas. This region has the youngest developmental history when it is compared with other areas in Vietnam. Accounting for nearly 50\% of the social workforce in the Mekong Delta, women have remarkable contributions to family, community, and social development. In the field of politics, female cadres actively learn to improve their political, professional, and moral qualities. In addition, women actively participate in building a powerful government, so a small percentage of women are trained, planned, promoted and appointed to many key positions in the local areas. However, women in the political system still confront many disadvantages in both quality and quantity when men are still dominant. This paper not only reveals female official's limitations in qualifications and specialist skills but also reflects gender inequality in decision-making positions.
\end{abstract}

Cited as: Linh, N.K., 2019. An evaluation female human resource in public administration with study case in the Mekong Delta. Can Tho University Journal of Science. 11(1): 104-111.

\section{INTRODUCTION}

In Vietnam, public administration has been called and understood as the State administration from 1945 to present. However, the name of public administration only has been used about 10 years. The administrative units are named after the boundary division of government levels from central to local. Vietnam's public administration reform strategy is widely known that it aims to change existing conditions of administrative mechanism. Moreover, the strategy satisfies the indispensable requirements for the new development of the country. To step up the efficient process of public administrative reform, Vietnamese Government has ratified two overall programs of administrative reform in the period of 2001-2010 and in the period of 2011-2020. In the two stages, Vietnam government confirms that it is necessary to improve the quantity of civil servant staff and their capacity, which meets demands of the process of national construction and development. Focusing on the development and enhancement of human resource in public administration, Resolution No. 30c/NQ-CP, dated on November 8th, 2011, Overall program of national public administrative reform the period of 2011-2020, also establishes long term goals of reform process. By 2020, cadres, civil servants and officials will reach a reasonable number in a well-planned structure. Moreover, these people will have enough capacity and competence to perform official duties, to serve the people and contribute their efforts to the development of the country (Vietnamese Government, 2011). Discussing on the importance of human resource development, Swanson and Holton (2001) states that it is "a process of developing and unleashing expertise for improving individual, team, work process, and organizational system performance". In other words, human resource development is considered as "a professional field of practice" (Swanson and Holton, 2001). 
The Mekong Delta (MD) is one of Vietnam's extensive areas. This region has the youngest developmental history compared with other areas in Vietnam. The MD has 12 provinces and a large city, and the public administration systems in these provinces are typically similar. The local administrative system complies with Constitution and Law on the foundation principle of Democratic Centralism in all activities. However, in the current stage, aside from the fact that Vietnam's public administrative system in general and the MD's public administrative system in particular have gained significant achievements, there still exist restrictions in most components in public administration system, especially in female human resource. Qualifications and professional skills of the female human resource generally cannot meet the social requirements as well as the demands of a modern administration. Besides, gender inequality exists in all fields and becomes one of remarkable problems not only in Vietnam but also in many countries in the world. In the MD, the difference of percentage between male and female in labor force is the highest if compared to the remaining areas of the country, being $17.6 \%$ ( $85.1 \%$ male, $67.5 \%$ female) (General Statistics Office, 2017). This gap is even larger in the urban areas. The number of women works in public administration and the rate of female with the leadership are noticeably low because men are still dominant in political system and generally have higher-ranking positions in all levels. This research, therefore, not only reflects a picture on current situation of female human resource in public administration but also discusses some detailed proposals to improve female civil servants in public administrative fields.

\section{MATERIALS AND METHODS}

To undertake this research, scientific research methods are used flexibly through following steps:

\subsection{Using concept thinking to confirm basic notions of theme}

Concept is a form of thought involving two components: connotation and denotation.

\subsection{Data collection: interview method and observation method}

The study was conducted in the MD of Vietnam the youngest area of Vietnam including 12 provinces and a big city. Local government system of the MD includes People's Councils and People's Committee at all levels such as provinces and a city, urban districts and rural districts, wards and communes. Besides, there are professional departments of province and city levels, professional offices of urban districts and rural districts. Because of similar characteristics in public administration structures in one city and 12 provinces in the $\mathrm{MD}$, the data were selectively collected from the authorities, departments and offices of three units including Can Tho City (Cai Rang urban district and Phong Dien rural district), Vinh Long Province (Binh Tan rural district) and Hau Giang Province (Chau Thanh A rural district).

For data collection, firstly, documents (both theories on public administration, human resource development and gender equality, official texts and official correspondences of all administrative institutions) were studied extensively. This process is useful to review related literatures and have knowledge about State's legal system and related policies. More importantly, information of female human resource at all local governments in the selected locations was collected. Secondly, the semi-structured interviews were conducted with representative interviewees such as managers and civil servants in public administration, combining a tape recorder. Besides, to stimulate respondents to produce more information, researcher uses probing such as the silent probe, verbal respondents and nonverbal respondents. With some participants in remote areas, the researcher conducted interviews via telephone. In addition, observation method will help researcher capture the valuable information through the directly interaction between the interviewer and the interviewee with gestures, words, attitudes, etc. while communicating.

\subsection{Data analysis}

Analyzing data relied on case study and interview method because they show what researcher expects. Firstly, case study has already mentioned in part of data collection. Hence, the collected data (both figures and theories) will be formulated into tables, charts and outline, the diagram for comparison or contrast, which will help researcher recognizes advantages and disadvantages of female human resource obviously even though researcher can observe the change of the quality and quantity in female human resource during a certain time. In most cases, valuable ideas from studying documents, patterns, even coming to conclusions will be displayed by causal maps and flow charts. To be more efficient, the researcher also uses statistical software of computer to handle data quickly. Secondly, with interview method, researcher can capture perspectives, emotion of interviewees, and from then, the researcher will discover the issue's nature. To display convincing results, two methods being used mainly for the 
process of data analysis are induction and deduction because they prove to be scientific and logical.

\section{RESULTS AND DISCUSSION}

According to Liberal feminism's perspective, women are encouraged to join the world of work, politics, and knowledge production. It is easy to recognize the influences of feminist praxis in public administration. Administrative processes have also been influenced by feminist praxis with the addition of the terms, if not the practice of, empowerment, participatory management and representative bureaucracy (D'Agostino and Levine, 2011). To build a feminist public administration, Liberal feminism wants women to take part in administrative staff, public institutions, and women achieve benefits of legal, political and social rights as well as those that men enjoy. Using individual men and the institutions and systems erected by a male - dominated society as the standards for equality assumes that the system is only flawed insofar as it is absent of women. (D'Agostino and Levine, 2011).

The Radical feminism claims that we need to abolish patriarchy if we want gender equality. Radical feminists consider gender system as the fundamental cause of women's oppression because the patriarchal system intentionally controls women through institutions, primarily institutions of heterosexuality and reproduction. Postmodern feminism focuses on value of difference. They argue that common feminist standpoint or "reality" is a typical example of how male language and culture to erase the valuable differences among women and among women and men. (D'Agostino and Levine, 2011).

Occupied nearly $50 \%$ of the social work force in the $\mathrm{MD}$, female laborers have made active contributions to the cause of family, community and society development. Nowadays, women in the MD can decide their life with bravery and confidence. It is easy to recognize their contribution to society in all aspects such as family and society, politics, economic, education and training, medical, science and technology, culture and sport, defense and security. Of these fields, education and training and healthcare are two areas with most women's participation.

With the increasing demands of the period of industrialization and modernization, the Vietnamese women in general and women in the MD in particular have been working in harmony with family and in the society. Women need to uphold moral values in the home and prepare their children to fulfil citizenship, which is practically known as "republican motherhood". Women cannot vote; however, they can impart "beauty, virtue, and refinement" to political gatherings. This is an important legitimating role in party - politics; therefore, this action raises them above their crassly masculine dynamics (Stivers, 2002). For family, women still have to fulfill their responsibilities of caring, raising and educating their children, especially women's influence on their family members. They become the keepers of the values of family's sustainable development and participate in deciding many important problems. Besides, they try to learn new knowledge values with the purpose of making their life condition better. Therefore, for the past years, the percentage of "cultural family" noticeably increases (over 80\%) (Women's Union of the MD, 2016). For society, women now have more opportunities to assert their roles and positions. Actually, women can take part in in more social activities than men do. Emulative movements such as "Women actively study, creatively work and contribute to happy family", and "Good work, good housework" have engaged many women, which play a significant part in development of the country. In Soc Trang province, $88.8 \%$ female civil servants and laborers achieve the title and reward of "Good work, good housework". Besides, many new models are built and developed effectively by women such as "Rice jar of love", "Save on electricity", "Every day every brick" (Women's Union of the MD, 2016). In general, women in the MD emulate in production and have a scientific method in work. They attempt to research and gain a lot of remarkable achievements, especially nowadays women can apply success of modern science and technology in production process. As a result, for instance, in Vinh Long province, 81.8\% of women are awarded with the title "Progressive women". (Women's Union of the MD, 2016).

\subsection{Women's typical characteristics in public administration at the MD}

Public administration of the MD has built an active and zealous civil servant force. Most public servants are from 30 to 40 years old (accounting for $60 \%$ of civil service); however, the group of 31-40 years old occupies the highest rate compared to the age groups. According to the province's statistic report in 2016 (Department of Home Affairs of Vinh Long, 2016), in Binh Tan rural district, Vinh Long province, the highest number is the age group of 3140 (51 persons), while the lowest number is the age group of 51-60 (22 persons) in 2016. Besides, over $60 \%$ of female officers is in the group of $31-40$ years old. For example, in Phong Dien rural district, Can Tho city, the number of female in the group of 31- 
40 years old is 17 persons (25 persons in total) in 2017. (Department of Home Affairs of Phong Dien rural district, 2017).

To develop on quality in public administration field, female officers are facilitated study to improve political knowledge, professional works, and office

Table 1: The number of public servants with certificates of politics at Rural District in 2016

\begin{tabular}{lrrr}
\hline Certificate of politics & $\begin{array}{r}\text { Binh Tan, Vinh } \\
\text { Long province }\end{array}$ & $\begin{array}{r}\text { Chau Thanh A, Hau } \\
\text { Giang province }\end{array}$ & $\begin{array}{r}\text { Phong Dien, Can Tho } \\
\text { city }\end{array}$ \\
\hline Intermediate & 18 & 26 & 28 \\
Advanced & 25 & 29 & 30 \\
\hline
\end{tabular}

Table 2: The number of public servants with certificates of politics at Commune level in 2016

\begin{tabular}{lrrr}
\hline Certificate of politics & $\begin{array}{r}\text { Binh Tan, Vinh } \\
\text { Long province }\end{array}$ & $\begin{array}{r}\text { Chau Thanh A, Hau } \\
\text { Giang province }\end{array}$ & $\begin{array}{r}\text { Phong Dien, Can Tho } \\
\text { City }\end{array}$ \\
\hline Intermediate & 158 & 55 & 95 \\
Advanced & 9 & 2 & 16 \\
\hline
\end{tabular}

Table 1 shows that in rural districts of the MD, the highest number of civil servant is in political advanced level; however, in communes, the greatest number of civil service is in political intermediate level. There is not much difference between intermediate level and advanced level in rural district areas (Table 1). However, female in public administration accounts for a relatively high rate in intermediate level of politics. For example, in Phong Dien rural district, Can Tho city, there are 09 female civil services (36\%) in total 25 female officers getting certificate of intermediate and only 03 persons have certificate of advanced. The number of civil servants with advanced level of politics is noticeably increasing in recent years. The reason can be because this level also is one of critical conditions for promotion in the political system. In commune areas (Table 2), Binh Tan rural district (Vinh Long province) has the greatest gap between levels, intermediate level predominates over advanced level, while the lowest difference gap is in Chau Thanh A rural district (Hau Giang province).

Compared to male counterparts, females have been showing many important and diversified contributions to local government's development. Therefore, in recent years, many typical women are selected, promoted, or appointed to different positions in public administration offices, even reach leadership positions. As a result, the number of women is increasing in local government and in Congress. For example, in Hau Giang province, 20.9\% (increasing $4 \%$ ) of females wins in election of People's Council at all levels in this period, and two of these are members of Congress (Women's Union of the MD, 2016). In $\mathrm{Ca} \mathrm{Mau}$ province, the percentage of female officers in People's Council at three levels is $28.8 \%$ (the last period is $23.2 \%$ ). In Vinh Long skills. All civil servants work in state administration have a certain understanding on politics. Competency on politics is divided into four types such as primary certificate, intermediate certificate, advanced certificate, and bachelor of politics.

province, there are 627 women in People's Council at all levels, especially, two of whom are Congress members and 547 female civil servants are managers in machinery of state (Women's Union of the MD, 2016). In Can Tho city, the rate of females in civil service is $28.57 \%$ at the poll of Congress and the percentage of women in People's Council is $29.07 \%$ at district (urban and rural) levels, and $27.40 \%$ at ward and commune levels. It is clear that problems of cadres are well recognized by related authorities and the role of female officers in making - decision position is affarmed in society (Women's Union of the MD, 2016).

\subsection{Limitations of female civil servant in public administration in MD}

Although Vietnam government has been performing two stages of public administration reform (20012010) and (2011-2020), and have emphasized the importance of cadres reformation. However, there still exist some restrictions in most components, especially in the female human resource in the MD's public administrative system.

\subsubsection{The weakness in qualifications and professional skills}

The participation of the female work force in the political system is important not only to ensure gender equity, but also to provide the basis for solving related issues such as human resource development, equitable payments, pensions, electoral reform, and services. However, the participation of women in the political system (the legislative and specialized offices) is still limited, so there is a big gender gap in the public administration. According to Striver (2002), public life needs the motherly efforts of women to temper the effects of masculine competitiveness and acquisitiveness, or female reformers 
have argued for this and society has accepted it. Striver (2002) thinks that women have the capacity to become leaders when he recognizes a majority of the settlement houses set up in poor neighborhoods are led and populated by women. It is clearly seen that women are at the forefront of social welfare policy advocacy. Therefore, promoting a greater participation of women in the government workforce can be a mean of enhancing social mobility (OECD, 2013).

Table 3: The average percentage of female civil servants in the MD from 2015 to 2017 (\%)

\begin{tabular}{rrrrrrr}
\hline Year & \multicolumn{2}{c}{ Can Tho } & \multicolumn{2}{c}{ Vinh Long } & \multicolumn{2}{c}{ Hau Giang } \\
\hline & $\begin{array}{r}\text { District (Urban// } \\
\text { rural) }\end{array}$ & $\begin{array}{r}\text { Ward/ Com- } \\
\text { mune }\end{array}$ & $\begin{array}{r}\text { District (Ur- Ward/ Com- } \\
\text { ban/ rural) }\end{array}$ & $\begin{array}{r}\text { District (Ur- Ward/ Com- } \\
\text { mune } \\
\text { ban /rural) }\end{array}$ & mune \\
\hline 2015 & 37.4 & 26.6 & 20.6 & 13.4 & 14.2 & 24.2 \\
2016 & 37.3 & 26.4 & 16.4 & 26.2 & 15.4 & 26.2 \\
2017 & 35.2 & 22.9 & 25.2 & 18.6 & 24.0 & 17.8 \\
\hline
\end{tabular}

(Source: Department of Home Affairs of Binh Tan rural district (Vinh Long province), Phong Dien rural district and Cai Rang urban district (Can Tho city), Chau Thanh A rual district (Hau Giang province), 2015-2017)

Can Tho city has the highest percentage of female civil servants in both district (urban/rural) and ward/commune levels from 2015 to 2017 . The number of women in districts usually is higher than that of women in wards/communes, for example, in Table 3 Can Tho city, $10.8 \%$ (2015), 10.9\% (2016) and $12.9 \%$ (2017). Another point is that Hau Giang province has the lowest difference between districts (urban/rural) and wards/communes with $6.2 \%$ (2017), while Can Tho city reaches to the highest difference with $12.9 \%$ (2017). In general, the number of female civil servants in local government of the MD is not high and there is obvious difference among areas.

Table 4: The average proportion of civil servants with qualifications and proficient competence in Commune in the period $(2015-2017)(\%)$

\begin{tabular}{lrrrrrrr}
\hline & \multicolumn{2}{c}{ Master Bachelor College } & Intermediate Primary & \multicolumn{2}{c}{$\begin{array}{c}\text { Foreign lan- Computer } \\
\text { guage (English) }\end{array}$} & skill \\
\hline Hau Giang province & 0.74 & 48.3 & 4.4 & 35.0 & 0.25 & 76.8 & 89.4 \\
Can Tho city & 2.0 & 55.6 & 2.0 & 32.5 & 0.0 & 66.2 & 84.1 \\
Vinh Long province & 0.15 & 31.5 & 1.0 & 53.8 & 13.5 & 16.0 & 24.0 \\
\hline
\end{tabular}

Table 5: The percentage of female civil servants with qualifications and proficient competence at Phong Dien rural district, Can Tho city in 2017

\begin{tabular}{crrrrrrr}
\hline $\begin{array}{c}\text { Total fe- } \\
\text { male }\end{array}$ & Master Bachelor & College & Intermediate & Primary & $\begin{array}{r}\text { Foreign language } \\
\text { (English) }\end{array}$ & $\begin{array}{r}\text { Computer } \\
\text { skill }\end{array}$ \\
\hline 25 & $1.6 \%$ & $76 \%$ & $0 \%$ & $0.8 \%$ & $0 \%$ & $76 \%$ & $88 \%$ \\
\hline
\end{tabular}

It can be recognized that traditional perspective in culture or custom of people in the MD is the important cause impacting to women's participation in public administration field. Actually, the role of male and female civil servants has been regulated since childhood. Children who are identified particular roles in society by their parents. Boys are expected to perform social roles while girls are trained to become mothers and wives for the future. This view is very backward, deeply ingrained in Vietnamese consciousness and passed on from generation to generation and strengthened daily through school, culture, law and media. However, today there is also a proportion of women with progressive views, those who have broken the traditional role (Bayes, 2011). Balance work - family is considered as the big issue that women must confront with in academia and how they can balance family and career at the same time. Women can give up the job and still feel happy and successful, but men cannot (D'Agostino and Levince, 2011). Finally, public administration is not the dominant field of women. Although there are some females becoming administrators, members of bureaus, government, most these offices employ women only in clerical capacities, and women trustees are rare (Bayes, 2011). Nowadays, education and medical still are two fields attracting a great number of females, especially females with high qualifications. The second reason for the difference in the number of female civil servants among areas is that the administrational units in district level (urban/rural) and ward/commune level are classified I, II, III. The standards of classification are based on Congress's regulations such as population, area, the level of eco-society development and geographical location. 
Nowadays, qualifications such as university degrees and office skills of female administrators in the public administration are relatively limited. This is the main reason why the number of women in leadership is not high.

Tables 4 and 5 show that most civil servants have university degree and certificates of language and computer skills. However, the proportion of civil service with master degree and college degree are very low (under 10\%), for example in commune level of Can Tho city, only $2 \%$ of women in public administration has master degrees, which is equal with the percentage of college degree. The number of officers with primary level is still high in Vinh Long province $(13.5 \%)$. The reason for this situation can be because of inadequacy in the training process. Nowadays, in Vietnam, there are two types of popular university training: full-time and continuing. For continuing training (work and study), it meets workers' conditions and demands. However, learners have various motivations including improving knowledge, satisfying job's requirements of organization, finding a job, creating promotional opportunities and legalization of titles. Secondly, although working in public administration, most cadres (males and females) are the title of professional and the great number of civil service have not trained administrative management so they do not have knowledge of public administration and work style. For example, according to the statistics report by the Department of Home Affairs of Vinh Long in 2016 , the number of officials with the professor title is 24 persons, but 94 persons did not have certificates of state management. Therefore, the problem of arranging work is difficult, and many staff have to work in areas other than that with professional knowledge. In addition, many female officials have certificates of computer skills and foreign languages in order to satisfy standards of the recruitment process, but they cannot use it proficiently, especially foreign language skill. Finally, backward point of view in society is "women do not need high education or high degree", housework is women's key responsibility.

\subsubsection{The low quantity in decision - making positions}

For many years, women have actively participated in leadership and management and are initially recognized and appreciated. However, if compared with the potential and resources of female staff in the political system, the proportion of female managers and leaders is still low. The ratio of male to female officials holding decision-making positions is still high, and decision-making power at all levels is still male. In particular, the rate of female leaders at commune and ward levels is very low.

Table 6: The number of female civil servants with leadership at Phong Dien communes level

\begin{tabular}{lrrrrrrrrr}
\hline \multirow{2}{*}{ Year } & \multicolumn{3}{c}{$\mathbf{2 0 1 5}$} & & & $\mathbf{2 0 1 6}$ & & $\mathbf{2 0 1 7}$ \\
\cline { 2 - 10 } & Total & Male & Female & Total & Male & Female & Total & Male & Female \\
\hline Number & 40 & 37 & 3 & 41 & 38 & 3 & 39 & 34 & 5 \\
Percent & & $92.5 \%$ & $7.5 \%$ & & $92.7 \%$ & $7.3 \%$ & & $87.2 \%$ & $12.8 \%$ \\
\hline
\end{tabular}

There are possible reasons for explaining the current situation of the low quantity.

\section{Strictness in evaluation activities}

In Vietnam, civil servants in public administration perform annual staff appraisal. This activity not only classifies civil services but also is a prerequisite for promotion, planning, and appointment of cadres to higher positions. This activity of appraisal of civil servants is based on the Law on Cadres, Civil Servants and Civil Servants Law.

Firstly, the important principle in evaluating and classifying cadres is that it must be "objective, fair and not repressive, biased or formatted". Although the assessment and classification are carried out by the heads of agencies and organizations, this evaluation is involved both staff managers in organizations and units. To conduct effective and objective evaluations, leaders and employees base on their responsibilities and tasks, the strengths and weaknesses in the capability of cadres. Secondly, the evaluation of civil services includes six criteria such as contents of political thought, ethics, capacity and professional style, efficiency of duties, responsibility and coordination, attitude towards service. Finally, this appreciation is result of classification with four levels "excellent completion", "good completion", "completion", and "failure to complete". "Failure to complete" is the lowest level when civil servants complete less than $70 \%$ of duties and violate disciplinary ethics. To achieve level 1 "excellent completion", civil servants not only accomplish $100 \%$ of tasks effectively, but also propose innovative or conduct research work. The evaluation is conducted by secret ballot in a meeting. (Vietnamese Government, 2015).

Female officers have made many efforts and achieved some typical achievements; however, it is 
very difficult for women administrators to gain level 1 and 2 of evaluation "excellent" and "good" because the working-environment, balance work and family, and promotion are objective factors affecting directly competence and motivation of women in job. Besides, the male leaders do not believe in the capacity of women. This viewpoint influences the election of female cadres for leadership when the votes of female officers are always lower than those of males. The subjective reason is that some female civil servants are not self-confident, and generally do not challenge high-ranking positions.

\section{Sex role stereotyping}

Sex role models become extremely important here. Firstly, in organization, an individual or a woman needs to look for one or two persons who have similar personal characteristics and positions to work in group. Besides, women who aspire to a higher promotion find some female leaders at higher levels with capacities and styles that they admire. It is easy for men to find male models with higher levels while examples of women are uncommon. Therefore, the lack of female role models in top organizational positions broadcasts a "no entrance" signal to the most qualified and interested women. Moreover, female leaders have to face a number of problems which male leaders in an organization do not have; isolation, for example, is one of these. Secondly, women

Table 7: The number of female official in commune level of Can Tho city, Vinh Long province and Hau Giang province

\begin{tabular}{lrrrrrrrrr}
\hline & \multicolumn{3}{c}{$\mathbf{2 0 1 5}$} & & & $\mathbf{2 0 1 6}$ & \multicolumn{3}{c}{$\mathbf{2 0 1 7}$} \\
\hline & Total & Male & Female & Total & Male & Female & Total & Male & Female \\
\hline Can Tho & 159 & 119 & 40 & 158 & 119 & 39 & 154 & 115 & 39 \\
Vinh Long & 220 & 189 & 31 & 233 & 196 & 37 & 220 & 179 & 41 \\
Hau Giang & 211 & 160 & 51 & 88 & 65 & 23 & 107 & 88 & 19 \\
\hline
\end{tabular}

(Source: Department of Home Affairs of Binh Tan rural district (Vinh Long province), Phong Dien rural district and Cai Rang urban district (Can Tho city), Chau Thanh A rual district (Hau Giang province), 2015-2017)

Table 8: The number of civil servant at Phong Dien rural district, Can Tho city (2015 - 2017)

\begin{tabular}{lrrrrrrrrr}
\hline \multirow{2}{*}{ Year } & \multicolumn{2}{c}{$\mathbf{2 0 1 5}$} & \multicolumn{3}{c}{$\mathbf{2 0 1 6}$} & \multicolumn{2}{c}{$\mathbf{2 0 1 7}$} \\
\cline { 2 - 9 } & Total & Male & Female & Total & Male & Female & Total & Male & Female \\
\hline \multirow{2}{*}{ Percent } & 81 & 55 & 26 & 79 & 53 & 26 & 84 & 59 & 25 \\
\hline
\end{tabular}

(Source: Department of Home Affairs of Phong Dien rural district, Can Tho city, 2017)

Actually, in Vietnam society, this is not the dominant field of women so the number of women only has from 25 to $30 \%$ if compared to men. In Hau Giang province, the number of women decreases noticeably from 51 persons (2015) to 19 persons (2017). According to general evaluation, the percentage of women in People's Councils at all levels has not increased significantly. Currently, in contrast to the number of women participating in the party committees, the ratio of women leaders in People's Councils is low and levels and lowest at the commune level (Table 7).

A possible problem in our country today is the thought of respecting men, which is still considerably popular, and to some extent women are discriminated. However, women have the capacity, and are as intellectual as men. They are entitled to receive 
an equal treatment and should enjoy the same benefits as men. Besides, in current years, public administration reform still has not overcome limitations in recruitment process in public administration. Currently, managers often base on curriculum vitae and personal relationships for the selection process. Typically, they do not rely entirely on job requirements. Women's equal participation in public administration and decision-making are a necessary condition for women's interests to be fully taken into account and properly addressed (UNDP, 2014). Without a critical mass of women, public administration is not tapping into the full potential of a country's workforce, capacity and creativity.

\section{CONCLUSIONS}

The study of women in public administration in the study area of the MD shows a general picture of the current situation of female civil servants in different levels of local government. In general, these are the young, enthusiastic and active female officials from 30 to 40 years old (over $60 \%$ of total civil servants). With the Constitution 2013 and the Law on Gender Equality 2006, women are now guaranteed rights, opportunities and conditions to develop, assert their positions and roles in many fields, especially the participation of women in leadership of agencies, local governments, and social organizations. However, the current situation is that the rate of women with qualifications and professional skills in public administration is relatively low; there are limited female cadres in decision - making positions. In addition, the difference of the ratio of men to women has caused the gender inequality in public administration. Compared with men, women are discriminated and treated unequally. It can be said that the thought of respecting men affects all aspects related to women. In fact, nowadays, modern women are as smart and talented as men because they have many opportunities to participate social activities with a high-level education. They have really gone beyond the family's housewife. Women in the $21^{\text {st }}$ century should be given all conditions to assert their roles, positions and inherit equal rights as men. Effective solutions with friendly family policy are necessary to help women balance between career and family.

\section{REFERENCES}

Bayes, J.H., 2011. Women and Public Administration: International perspectives. Routledge Publisher. New York, 135 pages.

D’Agostino, M.J. and Levine, H., 2011. Chapter 1 Feminist theories and their application to public administration. In: Hutchinson, J.R (Ed.). Women in Public Administration: Theory and Practice. Jones \& Bartlett Learning. United States, pp: 03-14.
Department of Home Affairs of Binh Tan rural district, 2017. The report of the quantity and quality of cadres and civil servants in Binh Tan district and commune from 2015 to 2017. Home Affairs Department. Binh Tan rural district (in Vietnamese).

Department of Home Affairs of Cai Rang urban district, 2017. The report of the quantity and quality of cadres and civil servants in Cai Rang urban district from 2015 to 2017. Home Affairs Department. Cai Rang urban district (in Vietnamese).

Department of Home Affairs of Chau Thanh A rural district, 2017. The report of the quantity and quality of cadres and civil servants in Chau Thanh A district and commune from 2015 to 2017. Home Affairs Department. Chau Thanh A rural district (in Vietnamese).

Department of Home Affairs of Phong Dien rural district, 2017. The report of the quantity and quality of cadres and civil servants in Phong Dien district and commune from 2015 to 2017. Home Affairs Department. Phong Dien rural district (in Vietnamese).

Eagly, A.H. and Johannesen-Schmidt, M.C., 2001. The leadership styles of women and men. Journal of Social Issues. 57(4): 781-797.

General Statistics Office, 2017. The Report on labor and employment survey. General Statistics Office. Ha Noi, 216 pages.

OECD, Organization for Economic Co-operation and Development, 2013. Women in Government. Government at a glance. OECD Publishing. pp: 119-127.

Stivers, C. M., 2002. Bureau men, settlement women: constructing public administration in the progressive era (studies in government \& public policy). University Press of Kansas. United States, 181 pages.

Swanson, R.A., and Holton, E.F.III., 2001. Foundations of Human Resource Development. Berrett - Koehler publishers, Inc. San Francisco, 437 pages.

UNDP, United Nations Development Program, 2014. Gender equality in Public administration. United Nations Development Program. New York, 68 pages.

Vietnamese Government, 2011. Decision No. 30c/NQCP, dated on November 8th, 2011, Overall program of national public administrative reform the period of 2011-2020, accessed on November 8th, 2011. Available from http://vbpl.vn/bonoivu/Pages/vbpq-toanvan.aspx?ItemID $=67957 \&$ Keyword= cai\%20cach\%20hanh\%20chinh\%20tong\%20the.

Vietnamese Government, 2015. Decision No. $56 / 2015 /$ ND-CP, dated on June 9th, 2015, Decree on evaluation and classification of cadres, civil servants, accessed on June 9th, 2015. Available from https://drive.google.com/file/d/1JDN0jZJYWfVNAu m4Gm_vuzBRyh5YagWN/view .

Women's Union of the MD, 2016. Evaluating women's movement and activities of Women's Union in Vinh Long province, Soc Trang province, Dong Thap province, Can Tho City, Ca Mau province, Hau Giang province, the period of 2011-2016. Women's Union of the MD. 